\title{
Atrial Cardiomyopathy and Atrial Fibrillation in Cancer
}

\author{
Mengdi Ren $\mathbb{D},{ }^{1}$ Yu Yao $\mathbb{D},{ }^{1}$ Xin Yue $\mathbb{D},{ }^{2}$ Yuye Ning $\mathbb{D},{ }^{3}$ and Yan Yang $\mathbb{D}{ }^{4}$ \\ ${ }^{1}$ Department of Oncology, The First Affiliated Hospital of Xi'an Jiaotong University, No. 277 Yanta West Road, \\ Xi'an 710061, China \\ ${ }^{2}$ Department of Cardiovascular Medicine, The First Affiliated Hospital of Xi'an Jiaotong University, No. 277 Yanta West Road, \\ Xi'an 710061, China \\ ${ }^{3}$ Department of Neurology, The First Affiliated Hospital of Xi'an Jiaotong University, No. 277 Yanta West Road, \\ Xi'an 710061, China \\ ${ }^{4}$ Department of Thoracic Surgery, The First Affiliated Hospital of Xi'an Jiaotong University, No. 277 Yanta West Road, \\ Xi'an 710061, China
}

Correspondence should be addressed to Yan Yang; yangyan3@xjtu.edu.cn

Received 26 November 2020; Revised 11 January 2021; Accepted 1 February 2021; Published 10 February 2021

Academic Editor: Tong Liu

Copyright ( $\odot 2021$ Mengdi Ren et al. This is an open access article distributed under the Creative Commons Attribution License, which permits unrestricted use, distribution, and reproduction in any medium, provided the original work is properly cited.

The number of patients with oncologic and cardiologic comorbidities is increasing. A growing number of evidence shows an inextricable link between cancer, atrial fibrillation, and atrial cardiomyopathy. Cancer itself and resultant inflammation, anticancer treatment, and other comorbidities lead to atrial remodeling and fibrosis, which increases the tendency to develop atrial cardiomyopathy and atrial fibrillation. The scarcity of current literature and ambiguous results make its relationship difficult to fully understand. In this review, we will summarize existing evidence of the relationships and interactions among cancer, atrial cardiomyopathy, and atrial fibrillation and discuss the underlying mechanisms, and provide better information for the management of these patients.

\section{Introduction}

Cancer patients have better survival nowadays due to multiple emerging therapies such as immunotherapy and target treatment. Therefore, cancer patients are more likely to suffer from cardiovascular disease (CVD) comorbidity. Cancer patients have more than twice the risk of fatal heart disease comparing to the general population [1]. A population-based study of CVD mortality risk shows that cancer patients are at elevated risk of dying from CVDs compared to the general population [2]. Recognition of the interaction between cancer and CVD has shifted from focusing on the cardiovascular toxicity of anticancer therapy [3] to the fact that they may share biological mechanisms that promote both malignancy and CVD development. One of the supporting evidence is that cancer survivors could have more cardiovascular abnormalities than the general population even without exposure to cardiotoxic treatment [4]. This naturally raises a question of whether this relationship is an association or causation between these two diseases, implying a new and exciting research realm in cardio-oncology.

Atrial cardiomyopathy, a term firstly described by Brigden in 1957 [5], affects the atria and atrioventricular system with the potential to produce arrhythmias $[6,7]$. The term has evolved for years. EHRA/HRS/APHRS/SOLAECE jointly published a consensus on atrial cardiomyopathies: "any complex of structural, architectural, contractile, or electrophysiological changes affecting the atria with the potential to produce clinically relevant manifestations" [8]. Medical community now agree that atrial fibrillation has strong causality with atrial cardiomyopathy because some instances of genetic diseases provide convincing evidence that underlying atrial tissue abnormalities may be the cause of AF rather than merely impact [9].

Several lines of evidence show that there is an inextricable connection between cancer and atrial fibrillation; however, no study has ever mentioned that this association may also exist in cancer and atrial cardiomyopathy. This 
review aims to summarize the existing evidence of the relationships and interactions among cancer, atrial cardiomyopathy, and AF, and we discuss the underlying mechanisms and provide useful information to improve the management of these patients.

\section{Atrial Fibrillation in Cancer}

$\mathrm{AF}$ is the most common type of heart arrhythmia. Here, we summarize the evidences supporting the relationship between AF and cancer (Table 1). AF can be induced by multiple cancer treatments such as immunotherapy, radiotherapy, surgery, and anticancer drugs [10]. Within 90 days after cancer diagnosis, the risk of AF was highest and this risk decreases over time [11].

Among all treatments, surgery may be the most frequently studied form of cancer-related AF. Several studies suggest that various types of cancer are associated with postoperative AF. A prospective study of 2588 thoracic surgery patients shows that malignant lung or esophagus cancer patients are more likely to develop postoperative AF than patients with benign disease [12]. About $4 \%-30 \%$ of patients after noncardiac surgery for malignancy would develop new-onset AF [12-16]. Meanwhile, the emerging of postoperative AF could predict a poorer long-term survival in lung cancer patients after receiving pulmonary lobectomy [17].But malignant tumor makes patients tending to suffer heavier burden of CVD and more invasive surgery form, making this association requiring more evidence to support.

In addition, cardiotoxicity of AF is a well-recognized adverse effect of certain chemotherapeutic drugs. For example, AF is a common complication induced by anthracyclines with the frequency of $2 \%-10 \%$ [18]. Persistent AF induced by anthracyclines is common and the first episode of AF event often occurs between 8 and 36 months after starting therapy [19]. AF could also occur in patients treated with other anticancer drugs such as fluorouracil, methotrexate, alkylating agents, antimicrotubule agents (docetaxel, paclitaxel), tyrosine kinase inhibitors (imatinib, lapatinib, sunitinib), proteasoma inhibitor (bortezomib), bevacizumab (blocker of the vascular endothelial growth factor), trastuzumab (angiogenesis inhibitor), and immune-checkpoint inhibitors [10,20-22], and this cardiotoxicity complication has been shown related to poor prognosis. A prospective study investigated 249 lymphoma patients treated with anthracyclines showing that new-onset AF may predict unfavorable outcomes after chemotherapy [19].However, the lack of cardiac monitoring before chemotherapy makes it difficult to distinguish whether there was a preexisting undiagnosed arrhythmia or accompanying arrhythmia caused by chemotherapy. However, some evidenceshows that the incidence of AF is higher in cancer patients even without treatment, which indicates that cancer itself may make patients vulnerable to AF [23].

Meanwhile, recent studies have demonstrated that the manifestation of the arrhythmia could occur preceding the diagnosis of the malignancy, implying that patients of AF are prone to a higher risk of cancer than the general population. In a follow-up cohort study (1980-2011) of 269,742 patients with new-onset AF based on a Danish registry database, $2.5 \%$ of the patients were diagnosed with cancer within 3 months, exceeding the expected rate based on national cancer incidence during the period [24]. A similar cohort study including 34,691 initially healthy women also demonstrated that new-onset atrial fibrillation was associated with a higher risk of subsequent cancer diagnosis [25]. A retrospective cohort study of 5130 patients with new-onset AF also confirms this conclusion with a $41 \%$ increase in cancer risk compared with the general population [26]. Of note, the risk is highest in the first three months following the diagnosis of AF while the risk declines after that. Thus, the existing evidence cannot support that AF could cause cancer, but only can suggest a correlation. There could be several interpretations for these data. Firstly, occult cancer may exist before patients were diagnosed of AF due to shared corisk factors. Regular medical follow-up and treatment for AF would increase the chance of early detection of potential cancer. Secondly, it is well known that patients of AF are prone to bleeding after anticoagulant drug therapy, which could promote the screening and intervention of early diagnosis of colorectal cancer. It is worth noting that antiarrhythmic drugs such as digoxin have estrogen-like effects and increase the risk of breast cancer in female AF patients [27].

Not all studies are in agreement with this correlation: a population-based, retrospective, matched cohort study suggests that women patients with early breast cancer may not have a higher prevalence of AF before cancer diagnosis [28]. However, such observation should be interpreted with caution since the prevalence of CVD and its risk factors is well known to be lower in women population.

The magnitude and mechanism of the interaction between AF and cancer are still unclear. Proposed mechanisms involved cancer-related inflammation, shared risk factors, anticancer treatment, and other related comorbidities, causing atrial remodeling and increasing the tendency to develop AF for cancer patients [29].

\section{Atrial Cardiomyopathy in Cancer}

There is no direct evidence for the association of atrial cardiomyopathy and cancer; however, several studies may provide some insights in this respect. Recent studies indicate that some embolic strokes of unknown source (ESUS) cases result from subclinical AF and atrial cardiomyopathy [30]. About $50 \%$ of cancer-associated strokes are ESUS [31]. A large population-based cohort study suggests that some cryptogenic strokes may be caused by occult cancer [32]. Hence, the stroke events of cancer patients may relate to subclinical AF and atrial cardiomyopathy.

Left atrial enlargement (LAE) on echocardiogram, evidence of left atrial abnormality demonstrated by increased p-wave terminal force in lead V1 (PTFV1) on ECG, and increased serum levels of a form of brain natriuretic peptide (NT-proBNP) and other markers for atrial disease have been used to define atrial cardiomyopathy [30]. The abnormality of these markers has been shown to be related to the cardiotoxicity and prognosis of cancer patients (Table 2). 
TABLE 1: Epidemiological evidence of AF in patients with cancer.

\begin{tabular}{|c|c|c|c|c|c|}
\hline Author & Cancer type & Study type & $\begin{array}{l}\text { Patient } \\
\text { number }\end{array}$ & Treatment & Correlation or hypothesis \\
\hline Ji-Hyun Chin & Esophageal cancer & $\begin{array}{c}\text { Retrospective } \\
\text { observational study }\end{array}$ & 583 & Esophagectomy & $\begin{array}{l}\text { Postoperatively developed AF was } \\
\text { associated with mortality in } \\
\text { esophageal cancer patients after } \\
\text { esophagectomy }\end{array}$ \\
\hline $\begin{array}{l}\text { Satoshi } \\
\text { Higuchi }\end{array}$ & $\begin{array}{l}\text { Head and neck; lung } \\
\text { cancer; gastrointestinal } \\
\text { cancer }\end{array}$ & $\begin{array}{l}\text { Prospective cohort } \\
\text { study }\end{array}$ & 799 & $\begin{array}{c}\text { Noncardiac surgery for } \\
\text { definitive/suspected } \\
\text { malignancy }\end{array}$ & $\begin{array}{c}\text { Perioperative atrial fibrillation in } \\
\text { noncardiac surgery was strongly } \\
\text { associated with perioperative } \\
\text { complications }\end{array}$ \\
\hline $\begin{array}{l}\text { Ara } \\
\text { A. Vaporciyan }\end{array}$ & Thoracic cancer & Prospective study & 2588 & Thoracic surgery & $\begin{array}{l}\text { The overall incidence of atrial } \\
\text { fibrillation was } 12.3 \%\end{array}$ \\
\hline $\begin{array}{l}\text { Chung-Wah } \\
\text { Siu }\end{array}$ & Colorectal cancer & $\begin{array}{l}\text { Retrospectively } \\
\text { study }\end{array}$ & 563 & $\begin{array}{l}\text { Elective abdominal } \\
\text { surgery }\end{array}$ & $\begin{array}{l}4.4 \% \text { patients developed } \\
\text { postoperative } \mathrm{AF}\end{array}$ \\
\hline $\begin{array}{l}\text { Andrea } \\
\text { Imperatori }\end{array}$ & Lung cancer & $\begin{array}{l}\text { Retrospectively } \\
\text { cohort study }\end{array}$ & 454 & Pulmonary lobectomy & $\begin{array}{l}\text { AF predicts poorer long-term } \\
\text { outcome in } 5 \text {-year survivors }\end{array}$ \\
\hline
\end{tabular}

TABLE 2: Atrial cardiomyopathy associated markers in patients with cancer

\begin{tabular}{|c|c|c|c|c|}
\hline Marker & Cancer & Anticancer therapy & Correlation & Reference \\
\hline \multirow{4}{*}{$\begin{array}{l}\text { Left atrial } \\
\text { enlargement }\end{array}$} & $\begin{array}{l}\text { HER2-positive breast } \\
\text { cancer }\end{array}$ & Trastuzumab (TZ) therapy & $\begin{array}{l}\text { LA dilatation associated with the } \\
\text { development of cardiotoxicity }\end{array}$ & $\begin{array}{l}\text { Corinna } \\
\text { Bergamini }\end{array}$ \\
\hline & Breast cancer & Anthracycline therapy & $\begin{array}{l}\text { Maximum LA volume significantly } \\
\text { increased in the patients }\end{array}$ & $\begin{array}{l}\text { Yalin Tolga } \\
\text { Yaylal }\end{array}$ \\
\hline & $\begin{array}{l}\text { Solid cancer (gynecological, } \\
\text { breast, gastrointestinal, } \\
\text { sarcoma, lungs) }\end{array}$ & Therapy-naive & $\begin{array}{l}\text { LA reservoir and conduit functions were } \\
\text { deteriorated in the cancer group }\end{array}$ & Marijana Tadic \\
\hline & Breast cancer & $\begin{array}{l}\text { Chemotherapy and } \\
\text { trastuzumab therapy }\end{array}$ & $\begin{array}{l}\text { Left atrial longitudinal strain as a } \\
\text { predictor of cancer therapeutics-related } \\
\text { cardiac dysfunction }\end{array}$ & Hyukjin Park \\
\hline \multirow{4}{*}{$\begin{array}{l}\text { ECG } \\
\text { abnormalities }\end{array}$} & Breast cancer & Anthracycline therapy & $\begin{array}{l}\text { Left intraatrial and interatrial } \\
\text { electromechanical intervals were } \\
\text { prolonged }\end{array}$ & $\begin{array}{l}\text { Yalin Tolga } \\
\text { Yaylal }\end{array}$ \\
\hline & $\begin{array}{l}\text { Chronic lymphocytic } \\
\text { leukemia (CLL) }\end{array}$ & Ibrutinib & $\begin{array}{l}\text { Left atrial abnormality identified by EKG } \\
\text { can identify patients at increased risk for } \\
\text { this toxicity. }\end{array}$ & \\
\hline & Multiple cancer & $\begin{array}{l}\text { Cardiac-directed radiation; } \\
\text { anthracycline and/or } \\
\text { alkylating chemotherapies }\end{array}$ & $\begin{array}{c}\text { ECG abnormalities are common among } \\
\text { childhood cancer survivors and } \\
\text { predictive of both cardiac and all-cause } \\
\text { mortality }\end{array}$ & $\begin{array}{l}\text { Daniel } \\
\text { A. Mulrooney }\end{array}$ \\
\hline & Left atrial myxoma & Tumor excision & $\begin{array}{c}\text { Increased PTFV1 correlates with the } \\
\text { tumor size }\end{array}$ & $\begin{array}{l}\text { Norihiro } \\
\text { Komiya }\end{array}$ \\
\hline \multirow{7}{*}{ NT-proBNP } & $\begin{array}{l}\text { Coronary artery disease free } \\
\text { of cancer } \\
\text { Neuroendocrine tumor } \\
\text { (NET) }\end{array}$ & - & $\begin{array}{l}\text { NT-proBNP is an independent predictor } \\
\text { of malignancies in patients with CAD } \\
\text { NT-proBNP are important markers in } \\
\text { the diagnosis and survival }\end{array}$ & $\begin{array}{l}\text { José Tuñón } \\
\text { Catharina } \\
\text { M. Korse }\end{array}$ \\
\hline & Multiple myeloma (MM) & Chemotherapy & $\begin{array}{l}\text { Elevated levels of NT-proBNP are } \\
\text { associated with disease severity }\end{array}$ & Noemi Pavo \\
\hline & $\begin{array}{l}\text { Differentiated thyroid } \\
\text { carcinoma }\end{array}$ & $\begin{array}{l}\text { Total thyroidectomy and } \\
\text { radioiodine ablation }\end{array}$ & $\begin{array}{l}\text { NT-proBNP associated with an increased } \\
\text { risk for cardiovascular events and all- } \\
\text { cause mortality }\end{array}$ & $\begin{array}{l}\text { Esther N. Klein } \\
\text { Hesselink }\end{array}$ \\
\hline & Cancer & - & $\begin{array}{l}\text { BNP levels are elevated and an indicator } \\
\text { of heart failure }\end{array}$ & Sachiko Bando \\
\hline & Breast cancer & $\begin{array}{l}\text { Not-high-dose } \\
\text { chemotherapy }\end{array}$ & $\begin{array}{l}\text { NT-proBNP detects high risk of } \\
\text { developing cardiotoxicity }\end{array}$ & S. Romano \\
\hline & Non-Hodgkin lymphoma & Chemotherapy & $\begin{array}{l}\text { NT-proBNP is a marker for risk } \\
\text { assessment for NHL patients }\end{array}$ & Eva Gimeno \\
\hline & $\begin{array}{l}\text { Metastatic renal cell } \\
\text { carcinoma }\end{array}$ & Sunitinib & $\begin{array}{l}\text { NT-proBNP predicts for clinical benefit } \\
\text { to sunitinib treatment }\end{array}$ & $\begin{array}{l}\text { Konstantinos } \\
\text { T. Papazisis }\end{array}$ \\
\hline
\end{tabular}


LA enlargement and dysfunction may relate with higher risk of cardiotoxicity during therapy in breast cancer $[33,34]$. Furthermore, a retrospective study including 92 therapy-naive cancer patients and their matched controls suggests that LA reservoir and functions are deteriorated in the cancer group [35]. Peak atrial longitudinal strain decline is a useful indicator of cancer therapeutics-related dysfunction in patients of breast cancer [36].

ECG abnormalities are common among cancer survivors, which can predict cardiac-cause mortality [37]. Although the major abnormalities are isolated ST/T wave abnormalities (7.2\%), evidence of myocardial infarction $(3.7 \%)$, and left ventricular hypertrophy with strain pattern $(2.8 \%)$ in this study, the markers for assessing atrial mechanical dysfunctions can also be detected in cancer patients. Moreover, left intraatrial and interatrial electromechanical intervals were prolonged in patients with breast cancer after anthracycline therapy [34]. A retrospective case-control study of chronic lymphocytic leukemia patients treated with ibrutinib indicated that left atrial abnormality identified by EKG is a predictor of atrial fibrillation [38]. In addition, the increasing size of left atrial myxoma brings about the broad negative P terminal force in lead V1 (PTFV1) [39].

NT-proBNP is a common and valuable marker regarding not only cancer but also therapy-related cardiac damage or prognosis. Firstly, NT-proBNP could be induced by oncologic diseases (such as invasive squamous cell carcinoma, malignant pericardial effusion, and small cell lung cancer) or related proinflammatory cytokines without cardiac failure [40, 41]. Secondly, NT-proBNP is an independent predictor of malignancies $[42,43]$. Its levels are related to disease severity of multiple myeloma (MM) without cardiac disease [44]. A study shows that NT-proBNP levels increased in patients with differentiated thyroid carcinoma and is associated with an elevated risk of cardiovascular events [45].Furthermore, some studies discovered a potential value of NT-proBNP as biomarker for cardiovascular events in cancer during anticancer therapy [43]. Normally NT-proBNP level could increase in cancer patients' plasma within 24 hours after the starting of chemotherapy without significant changes in the echocardiographic parameters and clinical sign $[46,47]$. The persistence of increased levels of NT-proBNP after the treatment may be helpful for the detection of patients with high risk of cardiotoxicity [47]. In addition, NT-proBNP was an independent indicator of survival time in patients of non-Hodgkin lymphoma [48] and a predictor for the progression of metastatic renal carcinoma [49].

The pathophysiologic mechanisms underlying the abnormal markers in cancer patients remain unclear. While it is frequently thought to be anticancer therapy-induced, cancer survivors without treatments can also present with abnormalities of these markers. Since there is no report on cancer patients complicated with atrial cardiomyopathy, it could raise a question of whether there is an underlying association between them. Existing research enrolled limited number of patients with various types of cancer and adopted different types of treatment in most studies. Well-standardized studies will be needed to better define the role of atrial cardiomyopathy and related markers in cancer.

\section{Mechanisms of Increased AF and Atrial Cardiomyopathy in Cancer}

As mentioned above, the risk of developing AF is increased for patients with cancer due to shared risk factors, treatments, and disease itself [50].

Oncologic and cardiologic diseases share many risk factors, such as advanced age, obesity, diabetes, and smoking, making the number of patients with comorbidities constantly increasing [51-54].

Antitumor therapy, including surgery, medication, and radiation, can result in atrial fibrillation. The exact mechanisms remain unclear, though it has been proposed that inflammation and apoptosis may be the decisive factors of cardiotoxicity during the treatment [29]. Fibrosis is a consequence of a nonspecific response to cardiomyocyte necrosis or apoptosis [55]. Anticancer therapy may contribute to AF through atrial fibrosis by apoptosis and inflammation.

For therapy-naïve cancer patients with increased incidence of AF, one alternative explanation is that proinflammatory states resulting from cancer itself can promote atrial fibrillation through atrial restructuring [23, 56-58]. Supportive evidence is that circulating levels of CRP, a marker representing the inflammatory state in cancer patients, is not only associated with the presence of AF but can also predict the risk of future development of AF $[56,59]$. In addition, pain, malnourishment, infections, and metabolic abnormalities are prevalent in patients with cancer and can result in dysregulated autonomous nervous system, which could also contribute to $\operatorname{AF}[52,60]$. Moreover, tumors or metastases adjacent to atrial tissues can directly cause AF by compressing the left atrium [61].

Over the past years, the investigation of AF has yielded fundamental insights into the pathophysiology of the electrical, mechanical, and structural abnormalities of the atrium [62]. The fundamental characteristic of the structural pathology associated with AF is atrial fibrosis and structural remodeling $[55,63]$. Atrial cardiomyopathy associated with AF includes myocyte degeneration and fibrotic changes of the connective extracellular matrix [55]. Therefore, it can be considered that atrial cardiomyopathy is the substrate for AF. As the atrial cardiomyopathy progresses, atrial dysfunction and eventually the AF develop [63]. Potential factors known to promote atrial fibrosis include aging, inflammation, and oxidative stress, which also could occur in cancer patients [63].

Based on the abovementioned theory, we can reasonably infer that atrial cardiomyopathy, AF, and cancer may interplay with each other on pathophysiological levels (Figure 1). Firstly, shared risk factors make cancer patients a high-risk group of atrial cardiomyopathy. Secondly, cancer itself and anticancer therapy may have direct effects on the LA substrate mediated by resultant systemic inflammation and apoptosis. Then, this pathological state would promote or result in fibrosis and structural remodeling of LA, which leads new-onset or existing atrial cardiomyopathy progress to atrial fibrillation. 


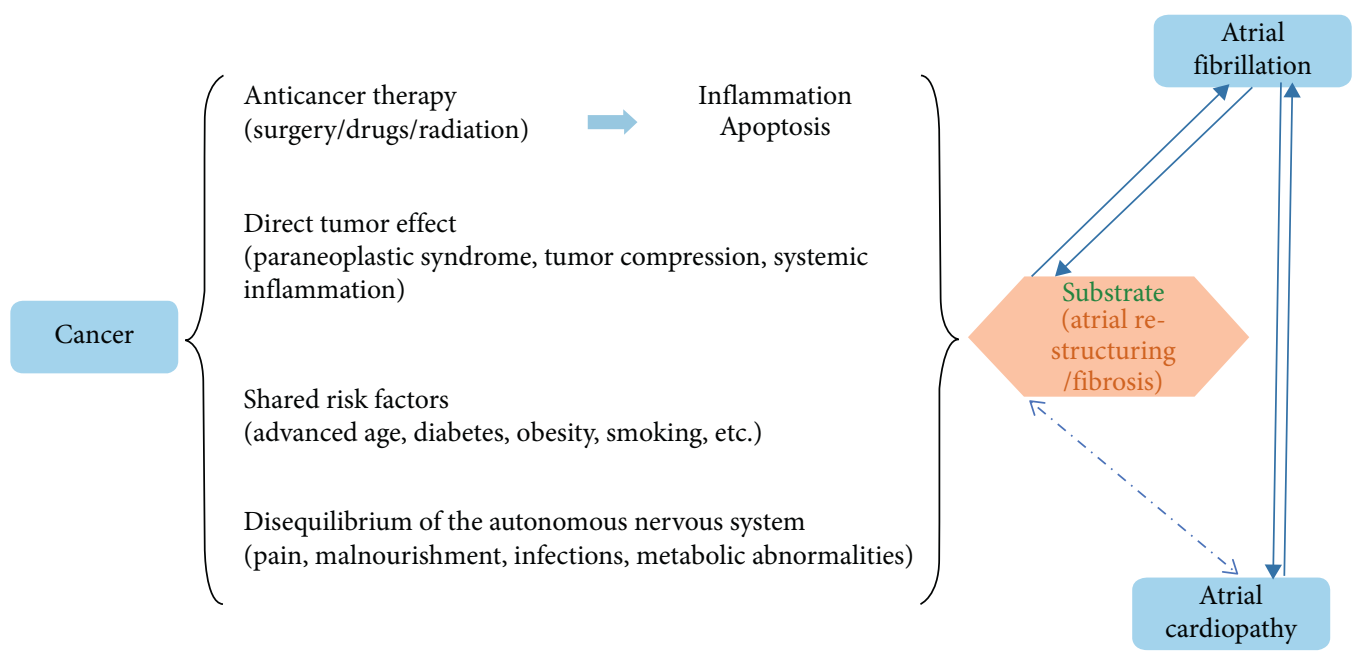

FIGURE 1: Schematic overview of the link between cancer, atrial fibrillation, and atrial cardiomyopathy. Shared factors may predispose to a comorbidity state of cancer, atrial cardiomyopathy, and atrial fibrillation. Cancer may cause atrial fibrillation and atrial cardiomyopathy by anticancer therapy, autonomous nervous system (ANS) imbalance, direct tumor effect, and other abnormalities. These factors may have direct effects on the left atria (LA) substrate and lead to systemic inflammation and apoptosis. Then, they promote or result in fibrosis and structural remodeling, leading new-onset or existing atrial cardiopathy progress to atrial fibrillation.

More studies are needed to explore the interaction between Cancer, AF, and atrial cardiomyopathy, which will provide crucial information on more individualized treatments.

\section{Challenges and Managements}

Given the increasing occurrence of the coexistent CVD in cancer patients, challenges of therapeutic strategies and management are vaster and more complicated than expected. The status of comorbidities and the deleterious effects of anticancer treatments often contribute to less effective treatment, poor life quality, and decreased survival.

The first problem is anticoagulation. Although it is recognized that cancer can lead to hypercoagulable state, the exact effect of cancer on thrombotic risk in patients with $\mathrm{AF}$ remains unknown [29]. The clinical recognition of atrial cardiomyopathy suggests a potential value on the identification of individuals at risk of stroke [64] and assessment of novel interventions designed for the prevention of AF [63]. Both atrial cardiomyopathy and cancer are involved in the prethrombotic state. A study showed that cancer patients, whether or not having AF, have an elevated risk of stroke than the general population [65]. However, the existing riskmodels that aid to starting anticoagulant therapy do not take the malignant tumor into account. Although the exact extent is not clear now, further related studies are needed to provide some insights in this respect. The clinical recognition of atrial cardiomyopathy in the cancer patients may help with better identification of high-risk patients with hypercoagulable state, which will improve their quality of life and overall survival.

Besides, the presence of CVD comorbidity would affect the clinical decision of cancer treatment and prognosis. Cancer patients with higher risk require cardiologic specialists' review and benefit assessment of anticancer therapy [66]. Multidisciplinary treatment (MDT) including both oncologic and cardiologic specialists would be best choice for patients of such comorbidity.

\section{Conclusion and Prospect}

With the increasing number of cancer patients with CVD, oncocardiology has become an emerging medical subspecialty focusing on cardiovascular effects of cancer and its treatment [67]. Even though the interaction of AF, atrial cardiomyopathy and cancer has been widely documented, the exact mechanism is still unclear. Cancer, possibly through inflammation or effects of the autonomic nervous system, predisposes patients to atrial cardiomyopathy and AF via atrial remodeling and fibrosis. Common risk stratification tools of anticoagulant therapy currently do not take cancer into account as a variable. The clinical value of looking into the atrial cardiomyopathy will provide new insights of this discipline but also the individualized treatment of disease, which will have meaningful implications for future anticancer and supportive treatment.

\section{Conflicts of Interest}

Authors declare no conflicts of interest in this article.

\section{Authors' Contributions}

Mengdi Ren and Yang Yan drafted the manuscript. Yuye Ning, Yu Yao, Xin Yue, and Yang Yan provided critical review and revision of the manuscript and YangYan approved the final draft for publication. 


\section{References}

[1] K. C. Stoltzfus, Y. Zhang, K. Sturgeon et al., "Fatal heart disease among cancer patients," Nature Communications, vol. 11, no. 1, p. 2011, 2020.

[2] K. M. Sturgeon, L. Deng, S. M. Bluethmann et al., "A population-based study of cardiovascular disease mortality risk in US cancer patients," European Heart Journal, vol. 40, no. 48, pp. 3889-3897, 2019.

[3] M. W. Bloom, C. E. Hamo, D. Cardinale et al., "Cancer therapy-related cardiac dysfunction and heart failure: part 1: definitions, pathophysiology, risk factors, and imaging," Circulation Heart Failure, vol. 9, no. 1, Article ID e002661, 2016.

[4] S. E. Lipshultz, D. C. Landy, G. Lopez-Mitnik et al., "Cardiovascular status of childhood cancer survivors exposed and unexposed to cardiotoxic therapy," Journal of Clinical Oncology, vol. 30, no. 10, pp. 1050-1057, 2012.

[5] W. Brigden, "Uncommon myocardial diseases the non-coronary cardiomyopathies*," The Lancet, vol. 270, no. 7008, pp. 1243-1249, 1957.

[6] A. Goette, J. M. Kalman, L. Aguinaga et al., "EHRA/HRS/ APHRS/SOLAECE expert consensus on atrial cardiomyopathies: definition, characterization, and clinical implication," Europace, vol. 18, no. 10, pp. 1455-1490, 2016.

[7] H. Kamel, P. M. Okin, M. S. V. Elkind, and C. Iadecola, "Atrial fibrillation and mechanisms of stroke," Stroke, vol. 47, no. 3, pp. 895-900, 2016.

[8] J.-B. Guichard and S. Nattel, “Atrial cardiomyopathy," Journal of the American College of Cardiology, vol. 70, no. 6, pp. 756-765, 2017.

[9] N. Stoyanov, J. Winterfield, N. Varma, and M. H. Gollob, "Atrial arrhythmias in the young: early onset atrial arrhythmias preceding a diagnosis of a primary muscular dystrophy," EP Europace, vol. 16, no. 12, pp. 1814-1820, 2014.

[10] J. Alexandre, J. J. Moslehi, K. R. Bersell, C. Funck-Brentano, D. M. Roden, and J.-E. Salem, "Anticancer drug-induced cardiac rhythm disorders: current knowledge and basic underlying mechanisms," Pharmacology \& Therapeutics, vol. 189, pp. 89-103, 2018.

[11] M. Yuan, Z. Zhang, G. Tse et al., "Association of cancer and the risk of developing atrial fibrillation: a systematic review and meta-analysis," Cardiology Research and Practice, vol. 2019, Article ID 8985273, 9 pages, 2019.

[12] A. A. Vaporciyan, A. M. Correa, D. C. Rice et al., "Risk factors associated with atrial fibrillation after noncardiac thoracic surgery: analysis of 2588 patients," The Journal of Thoracic and Cardiovascular Surgery, vol. 127, no. 3, pp. 779-786, 2004.

[13] J. H. Chin, Y. J. Moon, J. Y. Jo et al., "Association between postoperatively developed atrial fibrillation and long-term mortality after esophagectomy in esophageal cancer patients: an observational study," PloS One, vol. 11, no. 5, Article ID e0154931, 2016.

[14] S. Higuchi, Y. Kabeya, K. Matsushita et al., "Incidence and complications of perioperative atrial fibrillation after noncardiac surgery for malignancy," PloS One, vol. 14, no. 5, Article ID e0216239, 2019.

[15] C.-W. Siu, H.-M. Tung, K.-W. Chu, M.-H. Jim, C.-P. Lau, and H.-F. Tse, "Prevalence and predictors of new-onset atrial fibrillation after elective surgery for colorectal cancer," Pacing and Clinical Electrophysiology, vol. 28, no. s1, pp. S120-S123, 2005.

[16] V. Shrivastava, B. Nyawo, J. Dunning, and G. Morritt, "Is there a role for prophylaxis against atrial fibrillation for patients undergoing lung surgery?" Interactive CardioVascular and Thoracic Surgery, vol. 3, no. 4, pp. 656-662, 2004.

[17] A. Imperatori, G. Mariscalco, G. Riganti, N. Rotolo, V. Conti, and L. Dominioni, "Atrial fibrillation after pulmonary lobectomy for lung cancer affects long-term survival in a prospective single-center study," Journal of Cardiothoracic Surgery, vol. 7, p. 4, 2012.

[18] M. Guglin, M. Aljayeh, S. Saiyad, R. Ali, and A. B. Curtis, "Introducing a new entity: chemotherapy-induced arrhythmia," Europace, vol. 11, no. 12, pp. 1579-1586, 2009.

[19] M. Amioka, A. Sairaku, T. Ochi et al., "Prognostic significance of new-onset atrial fibrillation in patients with non-hodgkin's lymphoma treated with anthracyclines," The American Journal of Cardiology, vol. 118, no. 9, pp. 1386-1389, 2016.

[20] X. Yang, X. Li, M. Yuan et al., "Anticancer therapy-induced atrial fibrillation: electrophysiology and related mechanisms," Frontiers in Pharmacology, vol. 9, p. 1058, 2018.

[21] L. Cao, W. Zhu, E. A. Wagar, and Q. H. Meng, "Biomarkers for monitoring chemotherapy-induced cardiotoxicity," Critical Reviews in Clinical Laboratory Sciences, vol. 54, no. 2, pp. 87-101, 2017.

[22] B. Mery, J.-B. Guichard, J.-B. Guy et al., "Atrial fibrillation in cancer patients: hindsight, insight and foresight," International Journal of Cardiology, vol. 240, pp. 196-202, 2017.

[23] S. Guzzetti, G. Costantino, A. Vernocchi, S. Sada, and C. Fundarò, "First diagnosis of colorectal or breast cancer and prevalence of atrial fibrillation," Internal and Emergency Medicine, vol. 3, no. 3, pp. 227-231, 2008.

[24] E. B. Ostenfeld, R. Erichsen, L. Pedersen, D. K. Farkas, N. S. Weiss, and H. T. Sørensen, "Atrial fibrillation as a marker of occult cancer," PloS One, vol. 9, no. 8, Article ID e102861, 2014.

[25] D. Conen, J. A. Wong, R. K. Sandhu et al., "Risk of malignant cancer among women with new-onset atrial fibrillation," JAMA Cardiology, vol. 1, no. 4, pp. 389-396, 2016.

[26] C. S. Hung, C. H. Chang, J. W. Lin, Y. L. Ho, and M. F. Chen, "The association between new onset atrial fibrillation and incident cancer-A nationwide cohort study," PloS One, vol. 13, no. 6, Article ID e0199901, 2018.

[27] S. Wassertheil-Smoller, A. P. McGinn, L. Martin, B. L. Rodriguez, M. L. Stefanick, and M. Perez, "The associations of atrial fibrillation with the risks of incident invasive breast and colorectal cancer," American Journal of Epidemiology, vol. 185, no. 5, pp. 372-384, 2017.

[28] H. Abdel-Qadir, P. Thavendiranathan, K. Fung et al., "Association of early-stage breast cancer and subsequent chemotherapy with risk of atrial fibrillation," JAMA Network Open, vol. 2, no. 9, Article ID e1911838, 2019.

[29] G. Chu, H. H. Versteeg, A. J. Verschoor et al., “Atrial fibrillation and cancer - an unexplored field in cardiovascular oncology," Blood Reviews, vol. 35, pp. 59-67, 2019.

[30] S. Yaghi, H. Kamel, and M. S. V. Elkind, "Atrial cardiopathy: a mechanism of cryptogenic stroke," Expert Review of Cardiovascular Therapy, vol. 15, no. 8, pp. 591-599, 2017.

[31] B. B. Navi, S. Singer, A. E. Merkler et al., "Recurrent thromboembolic events after ischemic stroke in patients with cancer," Neurology, vol. 83, no. 1, pp. 26-33, 2014.

[32] B. B. Navi, A. S. Reiner, H. Kamel et al., "Arterial thromboembolic events preceding the diagnosis of cancer in older persons," Blood, vol. 133, no. 8, pp. 781-789, 2019.

[33] C. Bergamini, G. Dolci, A. Rossi et al., "Left atrial volume in patients with HER2-positive breast cancer: one step further to predict trastuzumab-related cardiotoxicity," Clinical Cardiology, vol. 41, no. 3, pp. 349-353, 2018. 
[34] Y. T. Yaylali, A. Saricopur, M. Yurtdas, H. Senol, and G. Gokoz-Dogu, "Atrial function in patients with breast cancer after treatment with anthracyclines," Arquivos brasileiros de cardiologia, vol. 107, no. 5, pp. 411-419, 2016.

[35] M. Tadic, M. Genger, C. Cuspidi et al., "Phasic left atrial function in cancer patients before initiation of anti-cancer therapy," Journal of Clinical Medicine, vol. 8, no. 4, 2019.

[36] H. Park, K. H. Kim, H. Y. Kim et al., "Left atrial longitudinal strain as a predictor of Cancer therapeutics-related cardiac dysfunction in patients with breast Cancer," Cardiovascular Ultrasound, vol. 18, no. 1, p. 28, 2020.

[37] D. A. Mulrooney, E. Z. Soliman, M. J. Ehrhardt et al., "Electrocardiographic abnormalities and mortality in aging survivors of childhood cancer: a report from the St jude lifetime cohort study," American Heart Journal, vol. 189, pp. 19-27, 2017.

[38] A. R. Mato, S. Clasen, P. Pickens et al., "Left atrial abnormality (LAA) as a predictor of ibrutinib-associated atrial fibrillation in patients with chronic lymphocytic leukemia," Cancer Biology \& Therapy, vol. 19, no. 1, pp. 1-2, 2018.

[39] N. Komiya, S. Isomoto, M. Hayano, T. Kugimiya, and K. Yano, "The influence of tumor size on the electrocardiographic changes in patients with left atrial myxoma," Journal of Electrocardiology, vol. 35, no. 1, pp. 53-57, 2002.

[40] J. Chovanec, M. Chovanec, and M. Mego, "Levels of NTproBNP and troponin T in cancer patients - mini-review," Klinicka Onkologie: Casopis Ceske a Slovenske Onkologicke Spolecnosti, vol. 33, no. 3, pp. 171-176, 2020.

[41] F. Wu and Q. Wu, "Corin-mediated processing of pro-atrial natriuretic peptide in human small cell lung cancer cells," Cancer Research, vol. 63, no. 23, pp. 8318-8322, 2003.

[42] J. Tuñón, J. Higueras, N. Tarín et al., "N-terminal pro-brain natriuretic peptide is associated with a future diagnosis of cancer in patients with coronary artery disease," PloS One, vol. 10, no. 6, Article ID e0126741, 2015.

[43] C. M. Korse, B. G. Taal, C. A. de Groot, R. H. Bakker, and J. M. G. Bonfrer, "Chromogranin-A and N-terminal pro-brain natriuretic peptide: an excellent pair of biomarkers for diagnostics in patients with neuroendocrine tumor," Journal of Clinical Oncology, vol. 27, no. 26, pp. 4293-4299, 2009.

[44] N. Pavo, A. Cho, R. Wurm et al., "N-terminal B-type natriuretic peptide (NT-proBNP) is associated with disease severity in multiple myeloma," European Journal of Clinical Investigation, vol. 48, no. 4, 2018.

[45] E. N. Klein Hesselink, A. N. A. van der Horst-Schrivers, I. C. C. van der Horst et al., "NT-proBNP is increased in differentiated thyroid carcinoma patients and may predict cardiovascular risk," Clinical Biochemistry, vol. 50, no. 12, pp. 696-702, 2017.

[46] S. Bando, T. Soeki, T. Matsuura et al., "Plasma brain natriuretic peptide levels are elevated in patients with cancer," $\mathrm{PloS}$ One, vol. 12, no. 6, Article ID e0178607, 2017.

[47] S. Romano, S. Fratini, E. Ricevuto et al., "Serial measurements of NT-proBNP are predictive of not-high-dose anthracycline cardiotoxicity in breast cancer patients," British Journal of Cancer, vol. 105, no. 11, pp. 1663-1668, 2011.

[48] E. Gimeno, M. Gómez, J. R. González et al., "NT-proBNP: a cardiac biomarker to assess prognosis in non-Hodgkin lymphoma," Leukemia Research, vol. 35, no. 6, pp. 715-720, 2011.

[49] K. T. Papazisis, L. F. Kontovinis, C. N. Papandreou et al., "Brain natriuretic peptide precursor (NT-pro-BNP) levels predict for clinical benefit to sunitinib treatment in patients with metastatic renal cell carcinoma," BMC Cancer, vol. 10, p. $489,2010$.
[50] B. M. Wollersheim, A. H. Boekhout, H. G. van der Poel, L. V. van de Poll-Franse, and D. Schoormans, "The risk of developing cardiovascular disease is increased for patients with prostate cancer who are pharmaceutically treated for depression," BJU International, vol. 125, no. 3, pp. 433-441, 2020.

[51] W. C. Meijers and R. A. de Boer, "Common risk factors for heart failure and cancer," Cardiovascular Research, vol. 115, no. 5, pp. 844-853, 2019.

[52] D. Farmakis, J. Parissis, and G. Filippatos, "Insights into oncocardiology," Journal of the American College of Cardiology, vol. 63, no. 10, pp. 945-953, 2014.

[53] T. Iwata, K. Nagato, T. Nakajima, H. Suzuki, S. Yoshida, and I. Yoshino, "Risk factors predictive of atrial fibrillation after lung cancer surgery," Surgery Today, vol. 46, no. 8, pp. 877-886, 2016.

[54] W. T. O’Neal, S. G. Lakoski, W. Qureshi et al., "Relation between cancer and atrial fibrillation (from the REasons for geographic and racial differences in stroke study)," The American Journal of Cardiology, vol. 115, no. 8, pp. 1090-1094, 2015.

[55] B. J. Hirsh, R. S. Copeland-Halperin, and J. L. Halperin, "Fibrotic atrial cardiomyopathy, atrial fibrillation, and thromboembolism," Journal of the American College of Cardiology, vol. 65, no. 20, pp. 2239-2251, 2015.

[56] R. J. Aviles, D. O. Martin, C. Apperson-Hansen et al., "Inflammation as a risk factor for atrial fibrillation," Circulation, vol. 108, no. 24, pp. 3006-3010, 2003.

[57] S. Nattel, B. Burstein, and D. Dobrev, "Atrial remodeling and atrial fibrillation," Circulation: Arrhythmia and Electrophysiology, vol. 1, no. 1, pp. 62-73, 2008.

[58] S. Nattel and M. Harada, "Atrial remodeling and atrial fibrillation," Journal of the American College of Cardiology, vol. 63, no. 22, pp. 2335-2345, 2014.

[59] K. H. Allin and B. G. Nordestgaard, "Elevated C-reactive protein in the diagnosis, prognosis, and cause of cancer," Critical Reviews in Clinical Laboratory Sciences, vol. 48, no. 4, pp. 155-170, 2011.

[60] P.-S. Chen, L. S. Chen, M. C. Fishbein, S.-F. Lin, and S. Nattel, "Role of the autonomic nervous system in atrial fibrillation," Circulation Research, vol. 114, no. 9, pp. 1500-1515, 2014.

[61] N. Ahmed, M. M. Carlos, G. Moshe, and R. Yitzhak, "Association between left atrial compression and atrial fibrillation: a case presentation and A short review of literature," Journal of Atrial Fibrillation, vol. 9, no. 2, p. 1458, 2016.

[62] R. S. Wijesurendra and B. Casadei, "Mechanisms of atrial fibrillation,” Heart, vol. 105, no. 24, pp. 1860-1867, 2019.

[63] J. J. Goldberger, R. Arora, D. Green et al., "Evaluating the atrial myopathy underlying atrial fibrillation," Circulation, vol. 132, no. 4, pp. 278-291, 2015.

[64] H. Kamel, A. E. Merkler, C. Iadecola, A. Gupta, and B. B. Navi, "Tailoring the approach to embolic stroke of undetermined source," JAMA Neurology, vol. 76, no. 7, pp. 855-861, 2019.

[65] C. J. Schwarzbach, A. Schaefer, A. Ebert et al., "Stroke and cancer," Stroke, vol. 43, no. 11, pp. 3029-3034, 2012.

[66] J. L. Zamorano, P. Lancellotti, D. Rodriguez Muñoz et al., "ESC position paper on cancer treatments and cardiovascular toxicity developed under the auspices of the ESC committee for practice guidelines: the task force for cancer treatments and cardiovascular toxicity of the european society of cardiology (ESC)," European Journal of Heart Failure, vol. 19, no. 1, pp. 9-42, 2016.

[67] J.-i. Abe, J. F. Martin, and E. T. H. Yeh, "The future of oncocardiology," Circulation Research, vol. 119, no. 8, pp. 896-899, 2016. 